Antarctic Science 26(2), 193-204 (2014) c) Antarctic Science Ltd 2013. The online version of this article is published within an Open Access environment subject to the conditions of the Creative Commons Attribution-NonCommercial-ShareAlike licence $<$ http://creativecommons.org/licenses/by-nc-sa/3.0/>. The written permission of Cambridge University Press must be obtained for commercial re-use.

\title{
Daily to intraseasonal oscillations at Antarctic research station Neumayer
}

\author{
N. RIMBU ${ }^{1,2}$, G. LOHMANN ${ }^{1}$, G. KÖNIG-LANGLO ${ }^{1}$, C. NECULA ${ }^{2}$ and M. IONITA ${ }^{\mathbf{1}}$ \\ ${ }^{I}$ Alfred Wegener Institute for Polar and Marine Research, Bussestrasse 24, \\ D-27570 Bremerhaven, Germany \\ ${ }^{2}$ University of Bucharest, Faculty of Physics, Bucharest, Romania \\ Norel.Rimbu@awi.de
}

\begin{abstract}
High temporal resolution (three hours) records of temperature, wind speed and sea level pressure recorded at Antarctic research station Neumayer $\left(70^{\circ} \mathrm{S}, 8^{\circ} \mathrm{W}\right)$ during $1982-2011$ are analysed to identify oscillations from daily to intraseasonal timescales. The diurnal cycle dominates the three-hourly time series of temperature during the Antarctic summer and is almost absent during winter. In contrast, the three-hourly time series of wind speed and sea level pressure show a weak diurnal cycle. The dominant pattern of the intraseasonal variability of these quantities, which captures the out-of-phase variation of temperature and wind speed with sea level pressure, shows enhanced variability at timescales of $\sim 40$ days and $\sim 80$ days, respectively. Correlation and composite analysis reveal that these oscillations may be related to tropical intraseasonal oscillations via large-scale eastward propagating atmospheric circulation wave-trains. The second pattern of intraseasonal variability, which captures in-phase variations of temperature, wind and sea level pressure, shows enhanced variability at timescales of $\sim 35, \sim 60$ and $\sim 120$ days. These oscillations are attributed to the Southern Annular Mode/Antarctic Oscillation (SAM/AAO) which shows enhanced variability at these timescales. We argue that intraseasonal oscillations of tropical climate and SAM/AAO are related to distinct patterns of climate variables measured at Neumayer.
\end{abstract}

Received 28 July 2012, accepted 29 May 2013, first published online 13 August 2013

Key words: climate variables, Madden-Julian Oscillation, Southern Annular Mode

\section{Introduction}

There is still a lack of knowledge about recent climate variations in Antarctica and their related teleconnections (e.g. Okumura et al. 2012). Due to limitations in spatial and temporal coverage of instrumental records spatial and temporal patterns of Antarctic climate have large uncertainty (Schneider et al. 2012).

Since March 1981 a German meteorological observatory programme has been carried out in Antarctica (e.g. KönigLanglo \& Herber 1996). Meteorological measurements were performed continuously at Neumayer Station (Georg von Neumayer Station: $70^{\circ} 37^{\prime} \mathrm{S}, 8^{\circ} 22^{\prime} \mathrm{W}$ ) from $1981-92$, at Neumayer II station $\left(70^{\circ} 39^{\prime} \mathrm{S}, 8^{\circ} 15^{\prime} \mathrm{W}\right)$ from $1992-2009$ and at Neumayer III $\left(70^{\circ} 40^{\prime} \mathrm{S}, 8^{\circ} 16^{\prime} \mathrm{W}\right)$ to the present. All three stations are, hereafter, referred to jointly as Neumayer Station. Various meteorological variables, which will be described in more detail below, have been measured regularly every three hours. These measurements, which now cover a period longer than 30 years, will be analysed to emphasize characteristics of regional Antarctic climate.
Oscillatory components are often detected in the climate system (e.g. Dima \& Lohmann 2004). In particular, the Antarctic climate is characterized by oscillations with a wide range of periods. In this study we investigate the Antarctic oscillations in the Neumayer region at timescales from one to 150 days. Up to $15-20$ days the variability is related to weather patterns. The intraseasonal band refers here to the variability on timescales of 20-150 days. A diurnal cycle was detected in different variables recorded at polar stations from Antarctica (e.g. Wang \& Zender 2011). This cycle is attributed to diurnal variation of the solar insolation. Intraseasonal oscillations over the Antarctic have been reported in previous studies. Air temperature and katabatic wind recorded at Japan's Mizuho Station show oscillations in the 30-50 day period (Yasunary \& Kodama 1993). These oscillations were linked to the modulation of the planetary flow regime and meridional circulation in the southern middle and high latitudes. An eastward propagating atmospheric circulation pattern in the stratosphere, with $\sim 30$ days period, was reported by Hsu \& Weng (2002). Analysis of high-resolution radar 


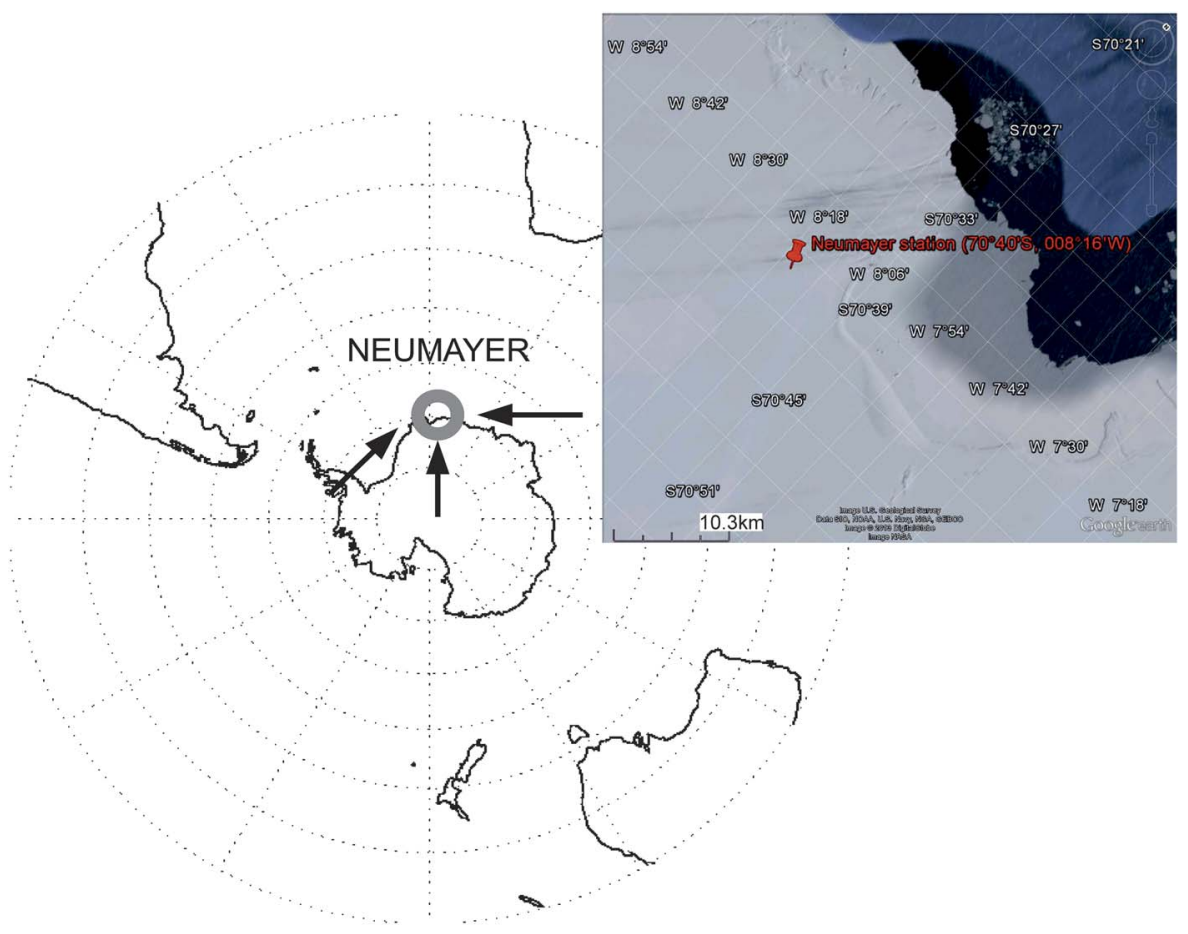

Fig. 1. Geographical position of the Neumayer Station (ring) and the dominant directions of the surface wind (arrows). Regional view of Neumayer area (upper right panel). measurements at Davis Base, Antarctica, reveals the existence of various oscillations in temperature and wind velocity in the 5-20 day interval and the 30-50 day interval, which were related to planetary wave activity (Stockwell et al. 2007).

One pattern with a significant impact on Antarctic climate variability is the Southern Annular Mode (SAM), also called the Antarctic Oscillation (AAO) (Thompson \&
Wallace 2000). The SAM/AAO is the leading mode of atmospheric low-frequency variability south of $20^{\circ} \mathrm{S}$. It consists of a seesaw pattern in the atmospheric pressure between the Antarctic region and the southern midlatitudes. The SAM/AAO shows enhanced variability at $\sim 4, \sim 9$ and $\sim 18$ days as well as in the intraseasonal band at $\sim 35, \sim 63$ and $\sim 117$ days (Pohl et al. 2010). Intraseasonal variations of sea level around Antarctica, with

Table I. Descriptive statistics of temperature (T), wind speed (U) and sea level pressure (SLP) records used in this study. Units are in ${ }^{\circ} \mathrm{C}, \mathrm{m} \mathrm{s}^{-1}$ and $\mathrm{hPa}$ respectively.

\begin{tabular}{|c|c|c|c|c|c|c|c|c|c|}
\hline Variable & $\begin{array}{l}\text { Temporal } \\
\text { resolution }\end{array}$ & Period & $\begin{array}{l}\text { Number of } \\
\text { observations }\end{array}$ & mean & $\min$ & $\max$ & median & $\mathrm{Q}_{0.25}$ & $\mathrm{Q}_{0.75}$ \\
\hline $\mathrm{T}$ & 3 hours & Year & 87391 & -16.1 & -49.8 & +2.6 & -15.1 & -22.8 & -8.0 \\
\hline $\mathrm{T}$ & 3 hours & Polar day & 15530 & -5.7 & -30.5 & +2.4 & -4.7 & -8.0 & -2.6 \\
\hline $\mathrm{T}$ & 3 hours & Polar night & 16202 & -23.0 & -49.8 & -2.3 & -22.2 & -29.2 & -16.8 \\
\hline $\mathrm{T}$ & 1 day & Year & 10751 & -16.1 & -43.9 & 0.96 & -15.3 & -22.7 & -8.0 \\
\hline $\mathrm{T}$ & 1 day & Polar day & 1989 & -5.1 & -19.8 & 0.96 & -4.9 & -7.6 & -3.0 \\
\hline $\mathrm{T}$ & 1 day & Polar night & 2074 & -23.2 & -43.9 & -5.8 & -22.7 & -28.9 & -17.5 \\
\hline $\mathrm{U}$ & 3 hours & Year & 87415 & 8.9 & 0.0 & 36.5 & 6.6 & 4.1 & 12.4 \\
\hline $\mathrm{U}$ & 3 hours & Polar day & 15531 & 7.5 & 0.0 & 33.9 & 7.2 & 4.1 & 11.8 \\
\hline $\mathrm{U}$ & 3 hours & Polar night & 16195 & 9.5 & 0.0 & 36.5 & 7.2 & 4.6 & 13.8 \\
\hline $\mathrm{U}$ & 1 day & Year & 10767 & 8.9 & 0.7 & 33.4 & 7.1 & 4.75 & 11.8 \\
\hline $\mathrm{U}$ & 1 day & Polar day & 1989 & 7.5 & 1.2 & 28.5 & 5.9 & 3.9 & 9.7 \\
\hline $\mathrm{U}$ & 1 day & Polar night & 2072 & 9.4 & 0.7 & 32.2 & 7.4 & 5.02 & 12.7 \\
\hline SLP & 3 hours & Year & 87427 & 986.8 & 930.3 & 1029.2 & 987.2 & 980.6 & 993.4 \\
\hline SLP & 3 hours & Polar day & 15526 & 987.9 & 949.1 & 1011.2 & 988.6 & 982.7 & 993.7 \\
\hline SLP & 3 hours & Polar night & 16204 & 987.8 & 941.5 & 1025.3 & 988.3 & 981.0 & 995.3 \\
\hline SLP & 1 day & Year & 10779 & 986.8 & 941.1 & 1027.2 & 987.1 & 980.7 & 993.2 \\
\hline SLP & 1 day & Polar day & 1991 & 988.2 & 955.6 & 1011.0 & 988.8 & 983.1 & 993.7 \\
\hline SLP & 1 day & Polar night & 2076 & 987.9 & 947.0 & 1022.4 & 988.16 & 981.2 & 995.2 \\
\hline
\end{tabular}



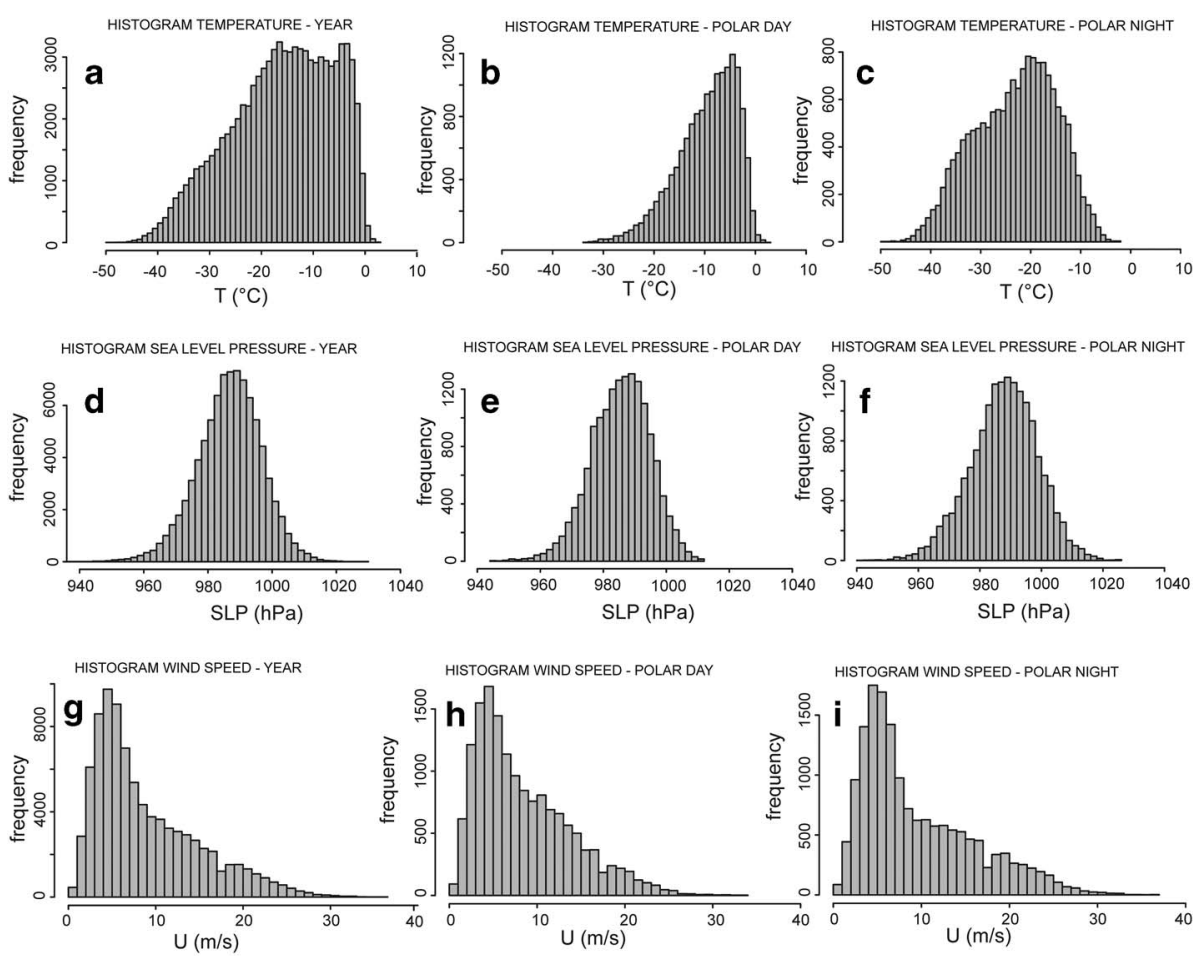

Fig. 2. Histogram of three-hourly measurements during the period 1982-2011 of a. temperature for all years, b. temperature for all polar days, c. temperature for all polar nights, d. sea level pressure for all years, e. sea level pressure for all polar days, f. sea level pressure for all polar nights, g. wind speed for all years, h. wind speed for all polar days, i. wind speed for all polar nights, j. wind direction for all years, k. wind direction for all polar days, l. wind direction for all nights.

periods varying from $10-100$ days, can also be related to SAM/AAO (Aoki 2002).

Pronounced oscillations in the intraseasonal band have been reported in the tropics, in particular the MaddenJulian Oscillation (MJO; Madden \& Julian 1994). The MJO is the dominant mode of atmospheric variability at the intraseasonal timescales, and shows enhanced variability in the 30-90 day period interval. It is associated with a mean eastward propagation of large-scale convective clusters from the Indian Ocean to the west Pacific basin (Madden \& Julian 1994). The extratropical teleconnections of MJO also affects Antarctic climate. Matthews \& Meredith (2004) found that intraseasonal variability of oceanic Antarctic circumpolar transport and the SAM/AAO are related to the tropical atmospheric MJO during the southern hemisphere winter. However, it is not clear if the most energetic fluctuations of the SAM/AAO, which range in the 30-60 day interval, are related to MJO (Pohl et al. 2010). Besides SAM/AAO, the Pacific South American Patterns 1 (PSA1) and 2 (PSA2) (e.g. Mo \& Higgins 1998) may play an important role in generating intraseasonal variations in Antarctica. The PSA1 and PSA2 modes, which show enhanced variability at $\sim 40$ days, were related to tropical convection and outgoing long-wave radiation (Mo \& Higgins 1998).

In this paper, we search for oscillatory signals in the time series of several meteorological variables measured at Neumayer Station (König-Langlo \& Loose 2007) with periods varying from hours to several months as well as the associated atmospheric circulation patterns. Oscillations and related teleconnections in the half-year to decadal band will be discussed in a forthcoming paper. Large-scale atmospheric circulation patterns associated with these oscillations are derived using reanalysis data from the whole Southern Hemisphere and compared with the dominant modes of variability at these timescales, i.e. MJO and SAM/AAO.

\section{Data and methods}

Systematic measurements of meteorological parameters have been carried out at Neumayer since 1981 (KönigLanglo \& Herber 1996). In March 1992 the observatory programme was transferred to the new Neumayer Station, 


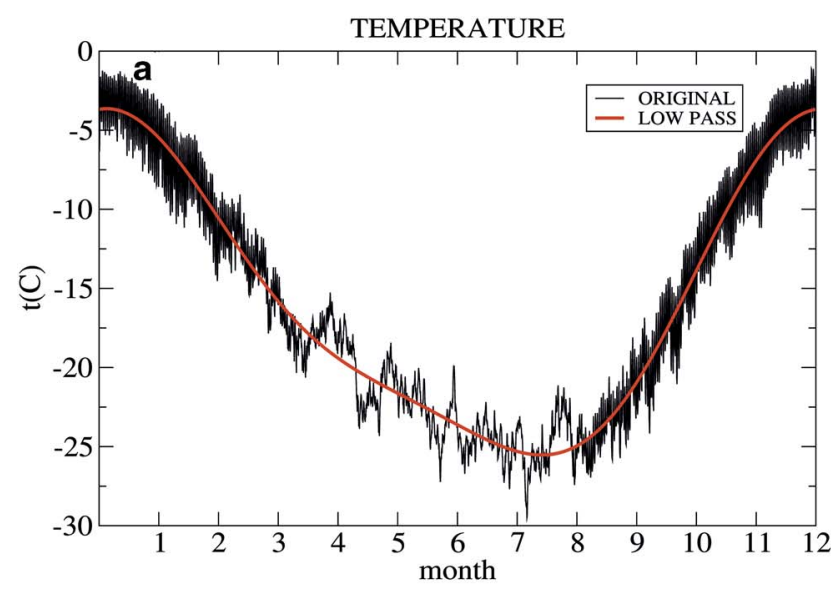

TEMPERATURE

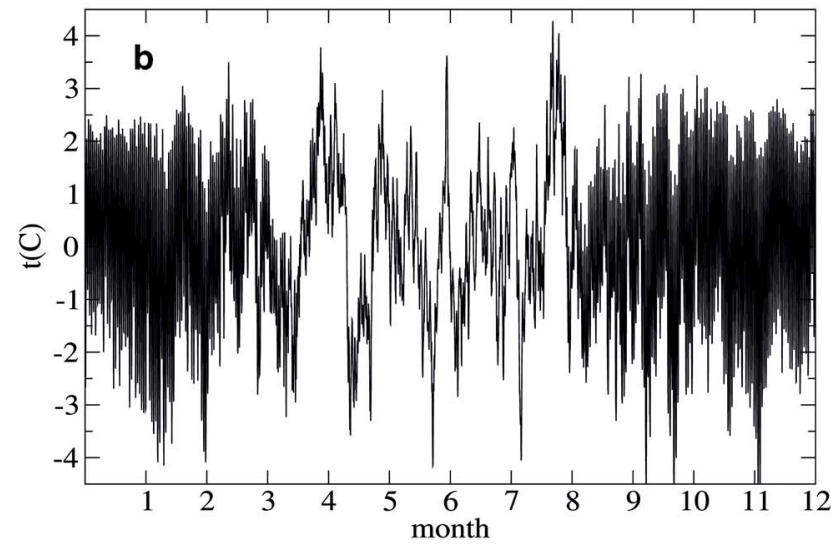

Fig. 3.a. Time series of the mean annual cycle of temperature with a three-hour resolution (original) and its low frequency part (low-pass). Low frequency part refers to timescales longer than 150 days. b. High frequency part of the mean annual cycle defined as the difference between mean annual cycle and its low frequency part represented in a. through black and respectively red curves.

i.e. the Neumayer II $\left(70^{\circ} 39^{\prime} \mathrm{S}, 8^{\circ} 15^{\prime} \mathrm{W}\right)$, located $8 \mathrm{~km}$ southeast of the former one. Since 2009 the meteorological observations have been performed at Neumayer III station $\left(70^{\circ} 40^{\prime} \mathrm{S}, 8^{\circ} 16^{\prime} \mathrm{W}\right)$. All stations are situated at the Ekström Ice Shelf on a homogenous flat surface, very gently sloping upwards to the south (Fig. 1). Observations of air temperature, air pressure, wind speed, wind direction, dew point temperature, clouds, horizontal visibility, and other several synoptic variables are carried out every three hours (0h00, 9h00, 12h00, 15h00, 18h00, 21h00 coordinated universal time) at Neumayer Station (König-Langlo \& Herber 1996, König-Langlo \& Loose 2007). The synoptic observations from Neumayer were carried out by a station meteorologist. A variety of redundant instruments as well as data visualization and validation (König-Langlo 2012) contribute to minimize errors. A detailed description of the instruments used and their accuracy is given by KönigLanglo \& Herber (1996).
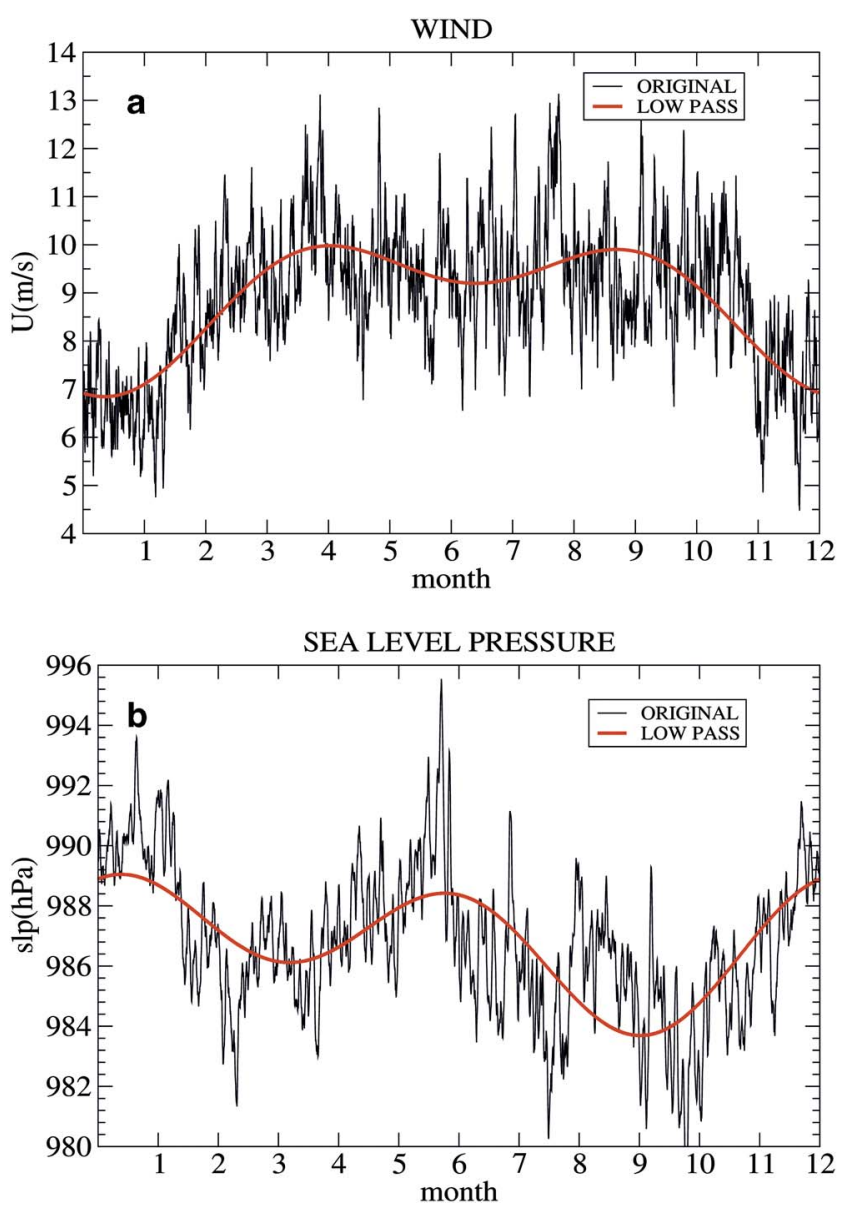

Fig. 4.a. Time series of the mean annual cycle of wind speed with a three-hours resolution (original) and its low frequency part (low-pass). Low frequency part refers to timescales longer than 150 days. b. As in a. but for sea level pressure.

The main quantities used in this study are the time series of three-hourly observations of air temperature (T), wind speed (U), and sea level pressure (SLP). These records are available from Publishing Network for Geoscientific \& Environmental Data network PANGAEA (http:// www.pangaea.de) (Rimbu et al. 2012). The records used in our study cover the period 1982-2011 (30 years). Each record has 87656 values $(8 \times 365 \times 30$ plus $7 \times 8$ due to leap years). The values of these variables are not available for all observational hours. However, the number of missing values is relatively small. In the T, U and SLP records only $0.3 \%$, $0.26 \%$ and $0.27 \%$ values are missing. From the original data (three-hourly observations) we have calculated daily mean time series. The daily means are calculated by averaging all the eight observations within a day. If there is at least one missing observation in a day, then the mean of that day is considered missing. To simplify the analysis we have excluded the 29 February observations from leap years. From the total number of days within the 1982-2011 interval, i.e. 10950 , only $1.81 \%$ are missing in the daily $\mathrm{T}$ record. 

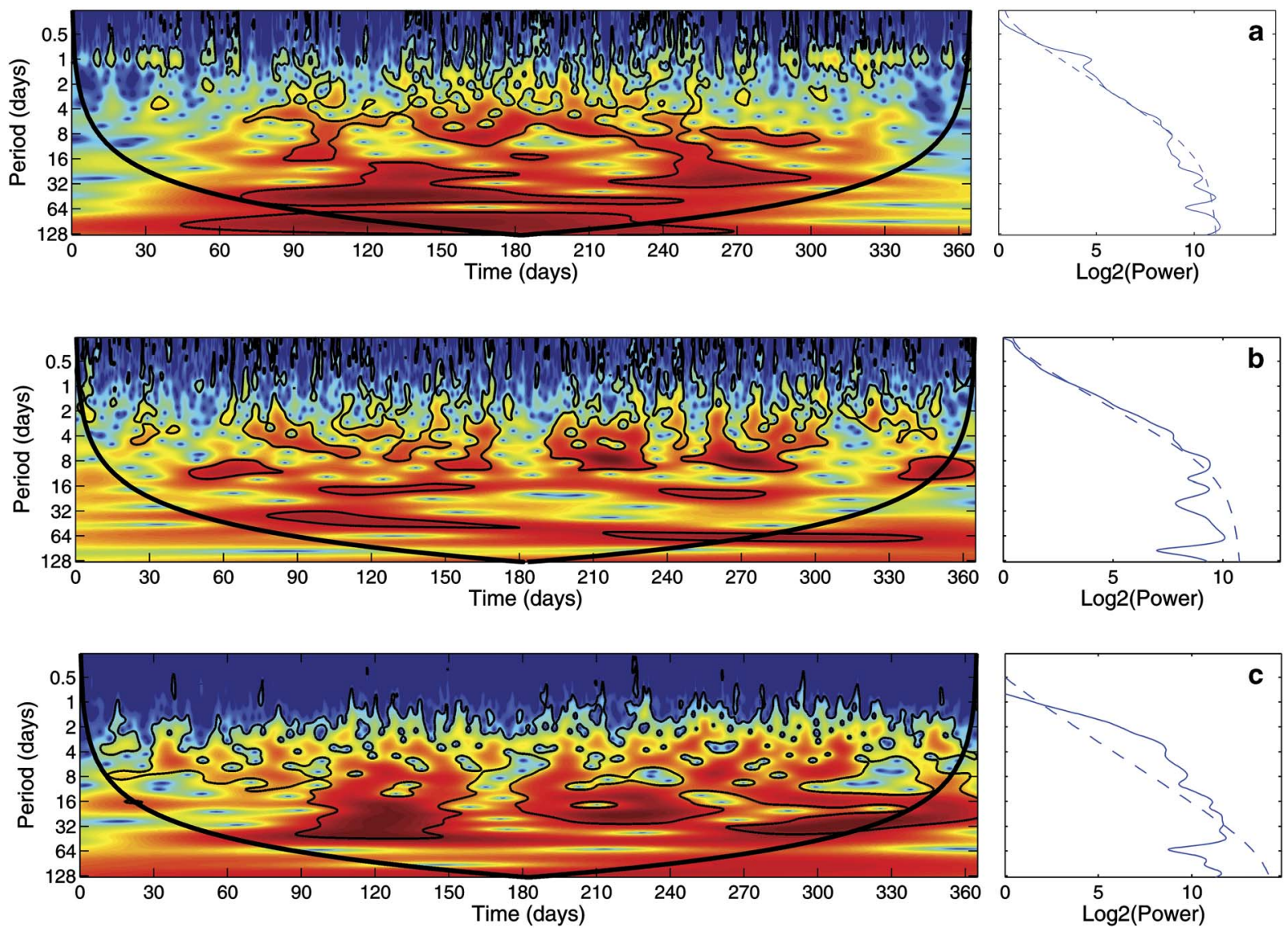

Fig. 5. a. The continuous wavelet spectrum of the high frequency component (timescales less than 150 days) of the 2010 year temperature (left) and the corresponding global power spectrum (right). The thick black contour is the $80 \%$ significance level against red noise. The cone of influence where edge effects might be relevant is indicated as thick black curve. Colours show power (or variance). The dashed line in the right panel represents the $80 \%$ significance level against the red noise. More details of the method are found in Torrence \& Compo (1998). b. \& c. as in a. but for 2010 year wind speed and sea level pressure respectively.

The daily U and SLP records have only $1.67 \%$ and $1.56 \%$ missing values respectively.

Statistical properties of three-hourly and daily T, U and SLP time series used in this study are summarized in Table I. These statistical parameters were calculated separately using all available values (all years), polar day (from 10 November-24 January) and for polar night (from 19 May-27 July). The statistical parameters of $\mathrm{T}, \mathrm{U}$ and SLP time series, calculated using all available measurements (Table I), are very close to those published in previous papers (e.g. König-Langlo \& Loose 2007). The range as well as the interquartile interval of $\mathrm{T}$ are higher during polar night than during polar day. The interquartile interval of $U$ as well as the range of SLP variations is higher during polar night than during polar day (Table I).

Statistical properties of data can also be summarized in histograms (Fig. 2). The histogram of all year $\mathrm{T}$ data (Fig. 2a) is skewed to the left. The relatively abrupt end of the right tail (Fig. 2a) is related to the melting barrier of the snow and ice in the region. In response to a favourable temperature increase, melting can take place. The associated modifications in the snow-ice surface energy budget lead to a limitation of temperature increase. The histogram of yearly $\mathrm{T}$ also shows two relatively small local maxima which are related to the $\mathrm{T}$ values corresponding to cold and warm seasons in the region (Fig. $2 b \& c$ ). The $\mathrm{T}$ distribution for polar day (Fig. 2b) is unimodal and asymmetric. Also in this case the abrupt decrease in the right tail of the distribution function is related to the snow-melting barrier effect. The distribution of $\mathrm{T}$ for polar night (Fig. 2c) presents less asymmetry than the corresponding distribution for polar day (Fig. 2b). Because all temperatures are negative, the decrease in the frequency in the right tail of the histogram is less abrupt than in the case of the polar day histogram. The histogram of polar night temperatures (Fig. 2c) suggests also a possible multimodality in the distribution function. The synoptic disturbances, which are associated with relatively warm air advection from the east toward Neumayer (König-Langlo \& Loose 2007), are responsible for the dominant maximum 

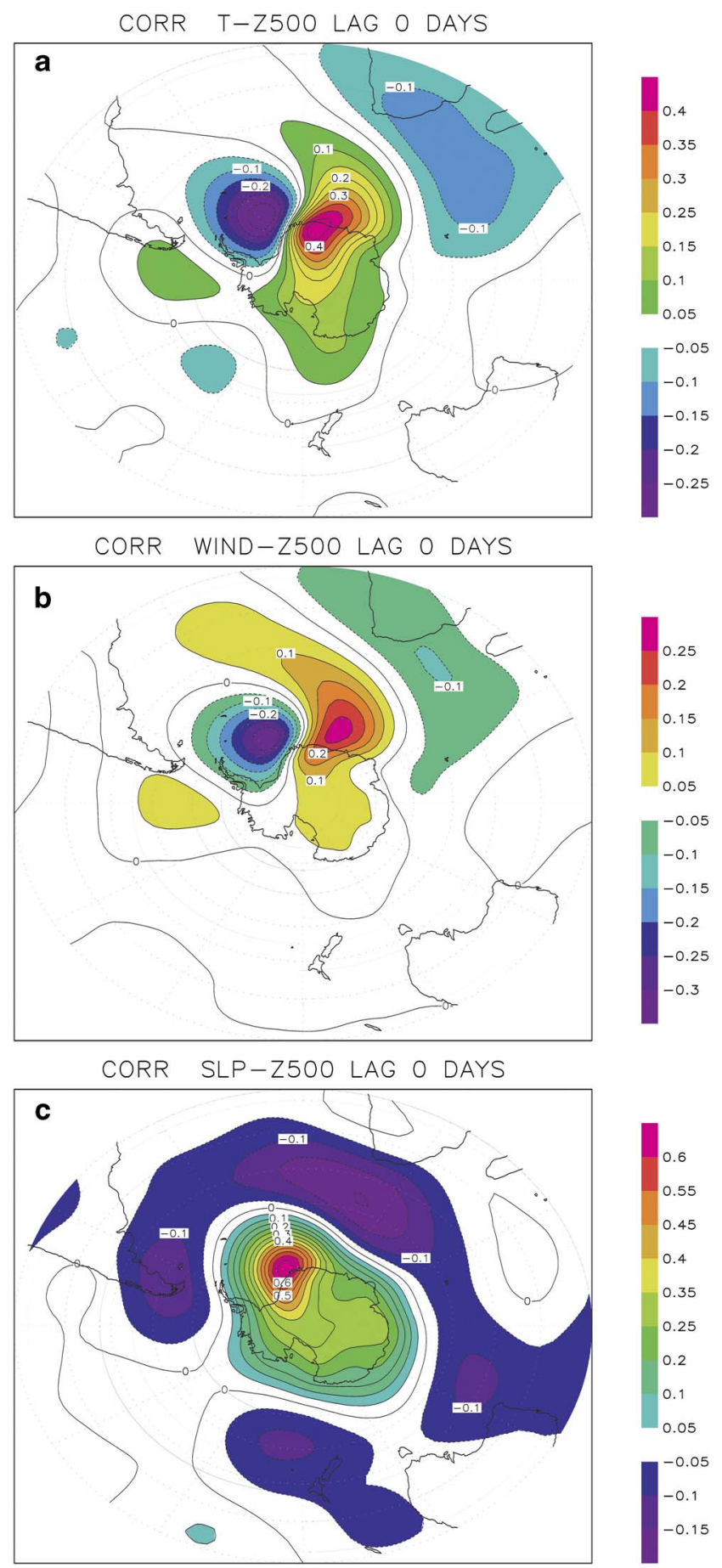

Fig. 6. Correlation map of a. temperature (T), b. wind speed (U), and c. sea level pressure (SLP) with $500 \mathrm{hPa}$ geopotential height. Low frequency components (timescales longer than 150 days) were removed from the data prior to the correlation.

in the polar night temperature histogram (Fig. 2c). The katabatic winds, blowing from the south bringing very cold air to Neumayer (König-Langlo \& Loose 2007), are responsible for the relatively small peak of $\mathrm{T}$ distribution near $-33^{\circ} \mathrm{C}$ during polar night (Fig. 2c). The SLP histograms all show bell-shaped distributions (Fig. 2d-f) suggesting a Gaussian probability distribution function of this variable. The histograms of $U$ (Fig. $2 \mathrm{~g}-\mathrm{i}$ ) shows a typical Weibull distribution (e.g. Justus et al. 1978). The histograms of the wind direction (Fig. 2j-1) show one prominent peak at about $90^{\circ}$ that is related to the typical synoptic disturbances in the region (König-Langlo \& Loose 2007). These histograms also show another two less pronounced peaks at about $170^{\circ}$ and $240^{\circ}$ which are associated with the katabatic and supergeostrophic winds, respectively, at Neumayer Station (König-Langlo \& Loose 2007).

To establish the atmospheric circulation patterns related to T, U and SLP variability at Neumayer, we have used the daily $500 \mathrm{hPa}$ geopotential height (Z500) extracted from the National Centers for Environmental Predictions (NCEP) and the National Center for Atmospheric Research (NCAR) (NCEP/NCAR) reanalysis database (http://www.esrl.noaa.gov/psd/data/reanalysis/reanalysis.shtml, accessed January 2012) for the period 1982-2011. The NCEP/ NCAR reanalysis dataset (hereafter NCEP1) is based on a global data assimilation system which uses input data from the original NCEP operational global T62 spectral model and various observations from multiple sources. The spatial resolution of the Z500 field used in our study is $2.5^{\circ}$ longitude $\times 2.5^{\circ}$ latitude. A detailed description of the NCEP/ NCAR global reanalysis data can be found in Kalnay et al. (1996) and Kistler et al. (2001). An improved version of the NCEP/NCAR global reanalysis data is the NCEP-Department of Energy (DOE) Reanalysis 2 dataset (hereafter NCEP2). The NCEP2 fixed errors and updated parametrizations of physical processes in NCEP1 (Kanamitsu et al. 2002). However, the results based on NCEP1 data were qualitatively the same as those based on NCEP2 so that only the results based on NCEP1 data will be discussed in this paper.

The time series of the MJO phase, as described by Wheeler \& Hendon (2004), for the period 1982-2011, was downloaded from the Centre for Australian Weather and Climate Research (CAWCR) webpage (http://cawcr/.gov.au/staff/mwheeler/ maproom/RMM/RMM1RMM2.74toRealtime.txt, accessed January 2012). To better assess and confirm the origin of intraseasonal oscillations from Neumayer we compare the frequency of MJO phases for the periods characterized by high and low values of the time coefficients of the dominant pattern of T, $U$ and SLP.

Empirical Orthogonal Functions (EOF) analysis (Von Storch \& Zwiers 1999) was used to identify the dominant patterns of T, U and SLP variability. The EOF method reduces a large number of variables to a few independent modes retaining much of the variance of the original data. Empirical Orthogonal Functions also filter out the noise from the data (Von Storch \& Zwiers 1999). We use correlation maps (Von Storch \& Zwiers 1999) to derive atmospheric circulation patterns associated to the dominant modes of intraseasonal variability of $\mathrm{T}, \mathrm{U}$ and SLP 


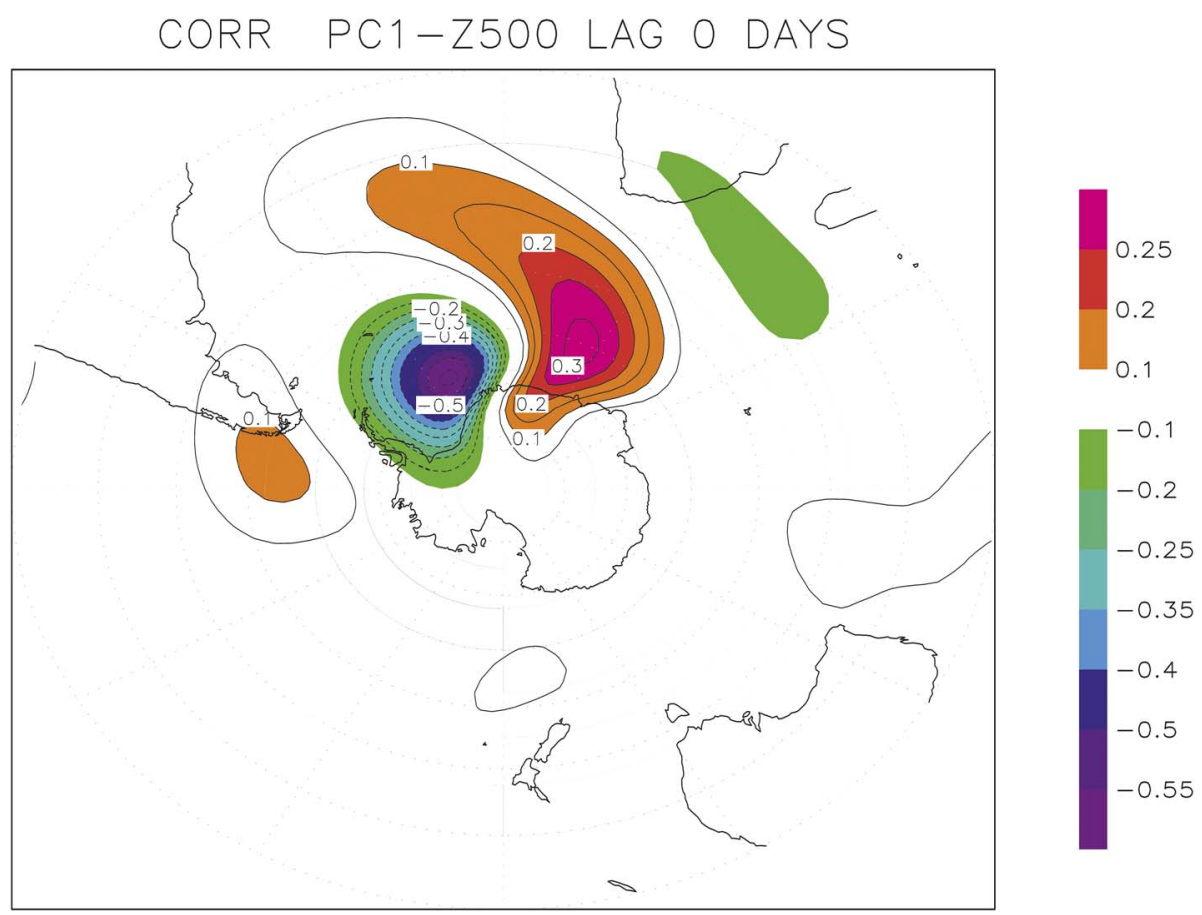

Fig. 7. Correlation map of the PC1 of temperature (T), wind speed (U) and sea level pressure (SLP) with 500 hPa geopotential height for lag zero. Low frequency components (timescales longer than 150 days) were removed from the data prior to the correlation.

measured at Neumayer. Singular spectrum analysis (SSA) (Ghil et al. 2002) was used to extract quasi-periodic signals from the time series. Singular spectrum analysis is a method for decomposition of a time series into a sum of a small number of independent and interpretable components such as slowly varying trends, oscillatory components and structureless noise (Ghil et al. 2002). The multi-taper method (MTM) was used for spectral estimation, which proved to be a useful tool for exploration of the spectral properties of signals that contain both broadband and oscillatory components (Ghil et al. 2002). Non-stationarity in the oscillatory signals is investigated using wavelet analysis (Torrence \& Compo 1998). Wavelet analysis is a spectral technique for analysis of localized variations of power within a time series. By decomposing a time series into time-frequency space, one is able to determine both the dominant modes of variability and how those modes vary in time (Torrence \& Compo 1998).

\section{Mean annual cycle of temperature, wind speed and sea level pressure}

The mean annual cycle of all variables considered in our study is defined as the average of all available measurements for each observational hour within a year over the period 1982-2011. The resolution of mean annual cycle is therefore three hours.

Temperature recorded at Neumayer presents strong variations within a year (Fig. 3a). The black curve in
Fig. 3a represents the mean annual cycle of temperature while the red curve stands for its low-pass filtered (timescales longer than 150 days) component, based on a Fourier filter applied to the mean annual cycle. This low-pass filtered component contains both annual and semi-annual oscillations. The mean temperature decreases continuously from January to July-August and increases relatively quickly from September to December. Similar variations were reported in previous studies for Neumayer (e.g. König-Langlo \& Loose 2007) and Faraday (Van den Broeke 1998) weather stations.

At Neumayer $\left(70^{\circ} 39^{\prime} \mathrm{S}, 8^{\circ} 15^{\prime} \mathrm{W}\right)$ the sun stays permanently above the horizon (polar day) from 19 November-24 January and permanently below the horizon (polar night) from 19 May-27 July. The polar day and polar night periods are associated with two distinct temperature variability regimes (Fig. 3b). High frequency variations are visible during polar day while relatively low frequency variations dominate during the polar night (Fig. 3b). A spectral analysis (not shown) reveals that polar day temperature variations are dominated by the diurnal cycle. This cycle is almost absent during the polar night. The relatively low frequency variation of temperature during polar night (Fig. 3b) reflects an increasing role of the atmospheric circulation and relatively low influence of radiative processes on temperature variability at Neumayer Station.

From mid-February to mid-March the wind speed shows an abrupt increase (Fig. 4a). The wind shifts back to lower values at the end of November and beginning of December. 


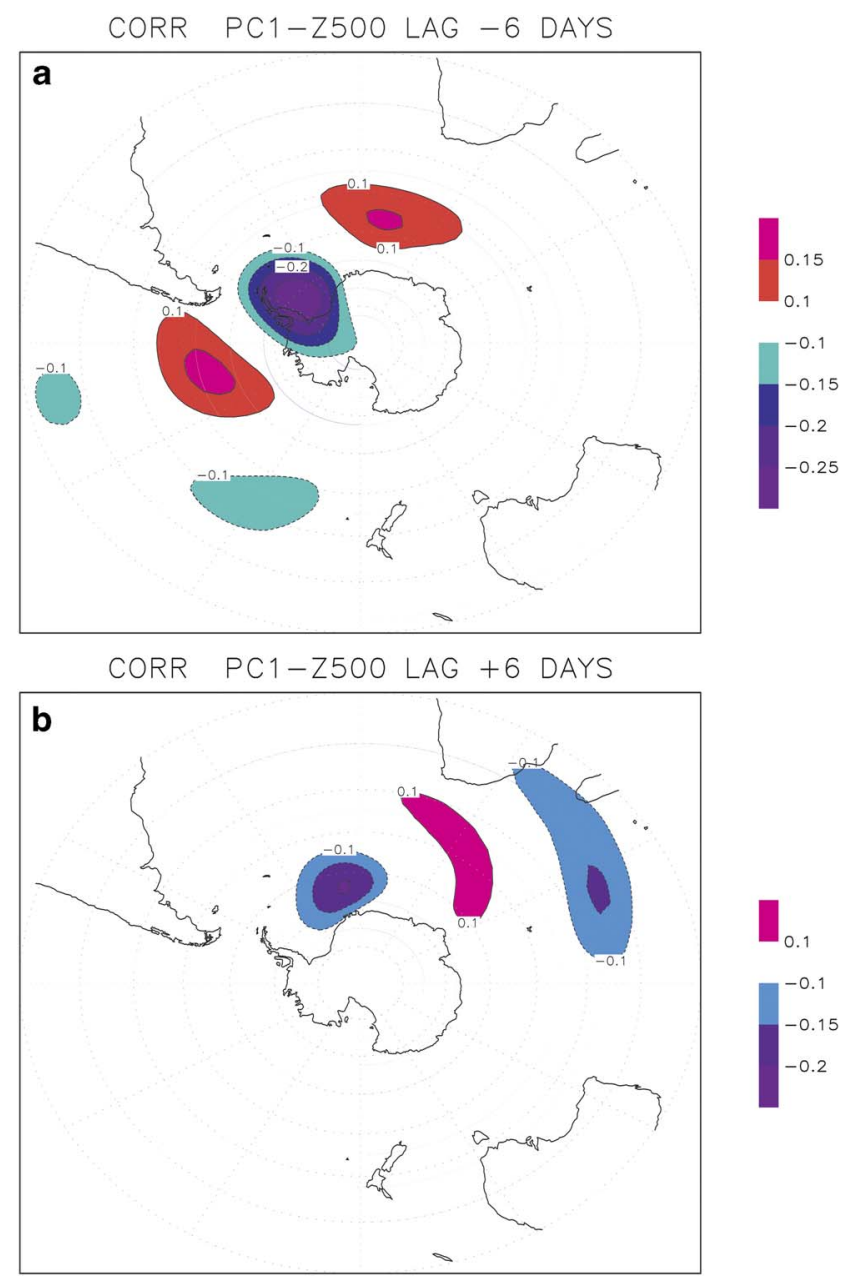

Fig. 8. Correlation map of the $\mathrm{PC} 1$ of temperature (T), wind speed (U) and sea level pressure (SLP) with $500 \mathrm{hPa}$ geopotential height for a. lag $=-6$ days, and b. lag $=6$ days. Low frequency variations (timescales longer than 150 days) were removed from the data prior to the correlation.

The low frequency component (timescale longer than 150 days) contains both annual and semi-annual oscillations. Within one year, the sea level pressure is relatively high at the end of December, January and June (Fig. 4b). Similar variations in the annual cycle of pressure were recorded at different Antarctic coastal stations close to the Neumayer Station (Van den Broeke 1998).

\section{Daily to intraseasonal oscillations of temperature, wind speed and sea level pressure and related atmospheric circulation patterns}

The spectral structure of the variability at timescales from three hours to 150 days is shown by a wavelet analysis of the three-hourly resolution time series of $\mathrm{T}$ (Fig. 5a), U (Fig. 5b) and SLP (Fig. 5c) recorded during the year 2010.

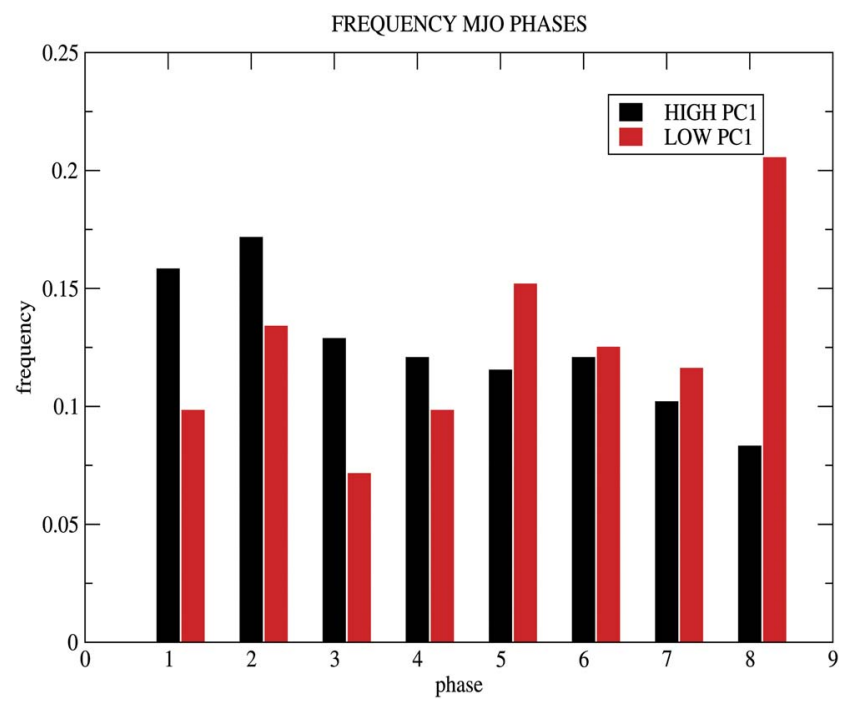

Fig. 9. Frequency of Madden-Julian Oscillation phases for periods characterized by high values of PC1 (black bars) and low values of PC1 (red bars).

We chose this particular year because the time series show temporal structures typical of the other years of the analysed period. Prior to the wavelet analysis the low frequency variations, i.e. timescales longer than 150 days, were removed using the Fourier filter. The wavelet spectrum of $T$ shows enhanced variability in several spectral bands (Fig. 5a). A persistent but non-stationary oscillation with a period of one day is clearly visible in the wavelet spectrum (Fig. 5a). It is relatively strong during the Antarctic summer and almost absent during Antarctic winter. A diurnal cycle is not evident in the wavelet spectrum of U (Fig. 5b) and SLP (Fig. 5c). Enhanced variability at $\sim 4$ to $\sim 8$ days is indicated by wavelet spectra of all variables, most clearly in U (Fig. 5). In the intraseasonal band the temperature record shows enhanced variability at $\sim 40$ days and $\sim 80$ days (Fig. 5a) while dominant periods for $U$ are $\sim 16$ days and $\sim 60$ days (Fig. 5b). Sea level pressure record shows a broad peak corresponding to a period of between $\sim 25$ and $\sim 35$ days (Fig. 5c). The intraseasonal variability is particularly strong during Antarctic winter for all variables (Fig. 5).

The correlation maps of T, U and SLP time series with Z500 for the period 1982-2011 shows different patterns (Fig. 6). Temperature (Fig. 6a) and U (Fig. 6b) variations are related with a wave-train pattern that extends from the South Pacific to the South Atlantic and Indian oceans. The highest correlations are recorded near Neumayer Station. During the positive phase of this pattern, enhanced advection of relatively warm air from the north-east induces relatively high temperatures at the station. This is consistent with the positive correlation $(r=+0.54)$ between $\mathrm{U}$ and $\mathrm{T}$ records. A reverse situation, i.e. low $\mathrm{U}$ and negative $\mathrm{T}$ anomalies are recorded at Neumayer during 


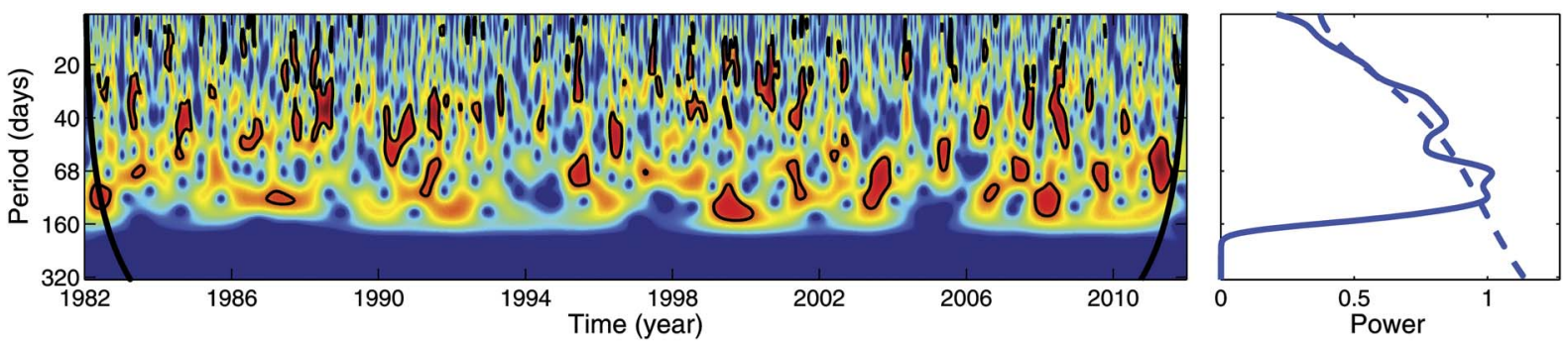

Fig. 10. The continuous wavelet spectrum of the PC1 of temperature (T), wind speed (U) and sea level pressure (SLP) (left) and the corresponding global power spectrum (right). The thick black contour is the $95 \%$ significance level against red noise. The cone of influence where edge effects might be relevant is indicated as light shadings. Colours show power (or variance). The dashed line in the right panel represents the 95\% significance level against red noise. More details of the method are found in Torrence \& Compo (1998).

the negative phase of this pattern. The correlation map of SLP with Z500 (Fig. 6c) shows an annular structure similar to SAM/AAO. There is a relatively weak projection of $\mathrm{T}$ or $\mathrm{U}$ and SLP related atmospheric circulation patterns (Fig. 6c).

\section{Patterns of temperature, wind and sea level pressure variability and associated atmospheric circulation anomalies}

The variables analysed here are obviously not independent of each other. The $\mathrm{T}$ is significantly positively correlated with $\mathrm{U}(r=+0.54)$ and negatively correlated with SLP $(r=-0.20)$. Wind speed is negatively correlated with SLP $(r=-0.37)$. To identify the common patterns of variability we perform an EOF analysis of the normalized daily time series of these variables. The time variations with timescales longer than 150 days were filtered out from these time series.

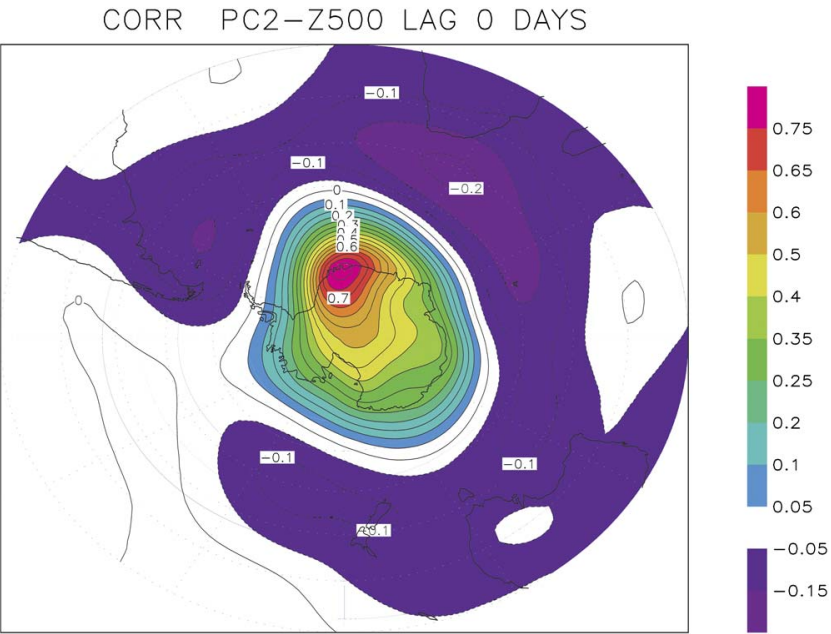

Fig. 11. Correlation map of $\mathrm{PC} 2$ of temperature (T), wind speed (U) and sea level pressure (SLP) with $500 \mathrm{hPa}$ geopotential height. Low frequency components (timescales lower than 150 days) were removed from the data prior to the correlation.
The first EOF (loadings are $+0.59,+0.65,-0.47$ ) describes $59 \%$ of the variance and captures the out-of-phase variations of $\mathrm{T}$ and $\mathrm{U}$ with SLP. This is consistent with the correlations between these variables reported above. The correlation of the associated time coefficients (PC1) with Z500 (Fig. 7) shows a wave-train pattern extending from the South Pacific to the Indian Ocean. The highest correlation ( $r=+0.6$ significant at $95 \%$ level) is recorded near Neumayer Station. The correlations are relatively low in the South Pacific Ocean. When this pattern is in a positive phase, enhanced advection of relatively warm air from north-east toward the station leads to positive temperature anomalies at the station. At the same time, SLP near the station is relatively low (Fig. 7). This pattern projects well on the T (Fig. 6a) and U (Fig. 6b) associated patterns, consistent with relatively high loadings of these variables in the leading EOF.

A lag-correlation analysis reveals that the wave-train pattern associated to $\mathrm{PC} 1$ (Fig. 7) propagates eastward. The correlation map of PC1 with Z500 anomalies when Z500 leads with six days (Fig. 8a) shows a wave-train pattern with relatively high correlations extending to the South Pacific sector relative to the lag-zero pattern (Fig. 7). Correlations in this area become non-significant for lag +6 days (Fig. 8b). Instead correlations increase in the Atlantic sector as lag-time increases from -6 days to 6 days (Fig. 8). This suggests a propagation of the signal from the South Pacific to the Atlantic sector.

The eastward propagation of the atmospheric circulation pattern associated with PC1 (Fig. 8) suggests a possible connection of intraseasonal climate variability in the Pacific sector with intraseasonal variability recorded at Neumayer. One important source of intraseasonal variability in the Pacific sector, which is the origin of the wave-train pattern associated with PC1 (Fig. 8), is the tropical region (e.g. Mo \& Higgins 1998). As the tropical variability presents well defined oscillations in the intraseasonal band (e.g. Mo \& Higgins 1998) we look for a direct connection between PC1 and the MJO. For this purpose we calculate the frequency of the MJO phases (Wheeler \& Hendon 2004) for the days 

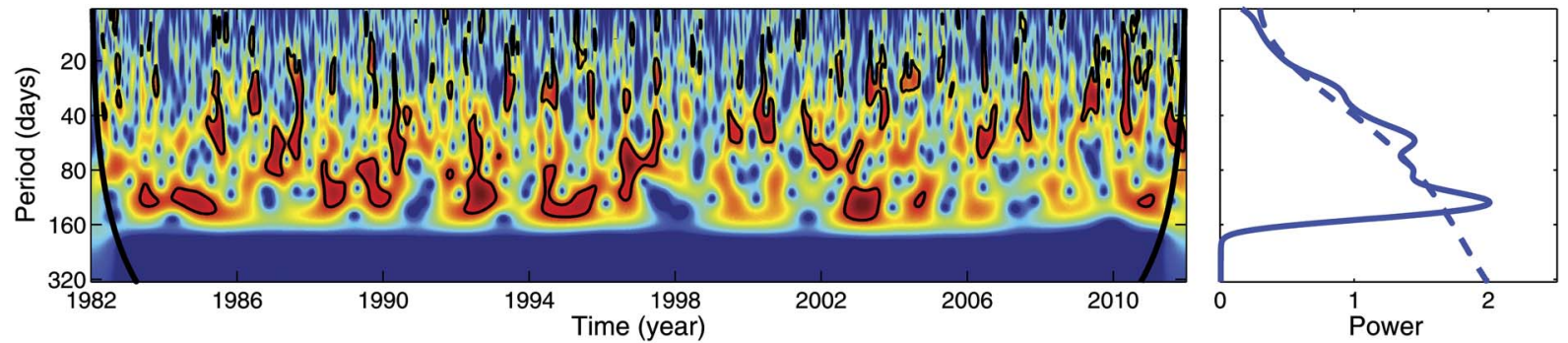

Fig. 12. As in Fig. 10 but for PC2.

when PC1 was higher than +2 standard deviation and compared with the frequency of MJO phases during the days when PC1 was lower than -2 standard deviation (Fig. 9). The results remain qualitatively the same for reasonable changes of these threshold values. As shown in Fig. 9, the frequency of 1 to $4 \mathrm{MJO}$ phases is higher for periods characterized by high values of $\mathrm{PC} 1$ relative to the periods characterized by low values of PC1. A reversed situation is observed for phases 5 to 8 (Fig. 9). The highest difference (significant at 95\% level) is recorded for phase 8 of the MJO.

Because the focus of this study is on the variability of Neumayer data at intraseasonal timescales we performed a wavelet analysis of a five-day mean PC1 values (Fig. 10). The wavelet spectrum shows that the intraseasonal oscillations are strongly non-stationary. Most of the significant oscillations occur at $\sim 40$ days and $\sim 80$ days, respectively. This is confirmed also by the global spectrum (Fig. 10, right panel) which shows significant ( $95 \%$ level) peaks at these timescales. To better assess and confirm the periodic signals shown by the wavelet spectrum (Fig. 10) we performed a Singular Spectrum Analysis of five-day mean PC1 values. The eigenspectrum of PC1 (not shown) presents two pairs of eigenvalues which correspond to two quasi-periodic signals (e.g. Ghil et al. 2002). The power spectrum of the reconstructed signal from these two SSA components shows a prominent peak at $\sim 40$ days and $\sim 80$ days (not shown), consistent with the wavelet spectrum (Fig. 10).

The second mode of $\mathrm{T}, \mathrm{U}$, and SLP intraseasonal variability captures in phase variations of these variables (loadings are $+0.52,+0.13,+0.83$ ). It describes $25 \%$ of the intraseasonal variance of these variables. The correlation of the associated time coefficients (PC2) with Z500 shows an annular structure (Fig. 11) that projects well on the negative phase of the SAM/AAO. It is similar to the circulation pattern associated with SLP variations (Fig. 6c). This was expected because the SLP loading dominates the EOF2. This pattern is associated with weak positive temperature anomalies at Neumayer Station. Consistent with this result, a recent study (Schneider et al. 2012) shows that SAM/AAO is negatively correlated with the temperature at Neumayer Station.

The wavelet spectrum of the five-day mean of PC2 values (Fig. 12) also shows significant oscillations in the intraseasonal frequency band at $\sim 35$ days, $\sim 60$ days and $\sim 120$ days. An SSA of PC2 (not shown) also reveals the existence of periodic signals at $\sim 35$ days, $\sim 60$ days and $\sim 120$ days in PC2.

\section{Discussions and conclusions}

We investigated the daily to intraseasonal variability of $T$, $\mathrm{U}$ and SLP recorded at Neumayer Station, located in the north-eastern Weddell Sea, Antarctica (Fig. 1). The records cover a period of 30 years (1982-2011) with three-hour resolution. The mean annual cycle of $\mathrm{T}$ presents specific spectral characteristics during the polar day (from November-January) relative to the polar night (from May-July). Polar day variations of $\mathrm{T}$ are dominated by the diurnal cycle while intraseasonal oscillations dominate the $\mathrm{T}$ variations during polar night. The diurnal cycle does not appear clearly in the three-hourly records of $U$ and SLP wavelet spectrum during either polar day or polar night. However, both U and SLP records show strong intraseasonal oscillations. During the polar night the temperature contrast between Antarctica and the surrounding oceans increases which allows warm air masses from the north to penetrate more deeply into Antarctica (Van den Broeke 1998). At longer timescales the mean annual cycle of these variables are dominated by semi-annual and annual oscillations (Fig. 4). Van den Broeke (1998) showed that, for the annual cycle of surface pressure recorded at several stations along the east Antarctic coast, the semi-annual oscillation accounts for $36-38 \%$ variance. A significant coupling between the semi-annual cycle of surface pressure and air temperature was detected and related with changes in meridional atmospheric circulation (Van den Broeke 1998).

Our EOF analysis isolated two patterns of daily to intraseasonal variability of T, $U$ and SLP. The first pattern captures the out-of-phase variations of $\mathrm{T}$ and $\mathrm{U}$ with SLP. The time coefficients associated with this pattern (PC1) show enhanced variability at $\sim 40$ days and $\sim 80$ days. Fluctuations at timescales of $\sim 40$ days were identified in other Antarctic climate variables. Kushner \& Lee (2007) isolated a regional atmospheric circulation pattern which propagates eastward within the SAM/AAO pattern. They identified two main periodicities, one of them being $\sim 40$ days. 
The existence of such an oscillation was confirmed by Pohl et al. (2010). Some authors related this oscillation to the tropical MJO which presents enhanced variability at these timescales (e.g. Madden \& Julian 1994). However, it is not clear if the $\sim 40$ day oscillation can be related to the MJO signature in Antarctic climate or if it is an intrinsic mode of SAM/AAO variability. Our lag-correlation analysis suggests that the $\sim 40$ day periodicity in the Neumayer variables is related to South Pacific intraseasonal variability which is strongly influenced by the MJO (e.g. Donald et al. 2006). Furthermore, a composite analysis reveals that the frequency of phase 8 of MJO is significantly higher during periods characterized by low values of $\mathrm{PC} 1$ relative to periods characterized by high values of PC1. This is another indication that the atmospheric circulation wavetrain associated with $\mathrm{PC} 1$ and the corresponding periodicities are related to tropical MJO.

The atmospheric circulation pattern associated with PC1 of T, U and SLP from Neumayer contains elements of the Pacific South American (PSA) patterns (e.g. Mo \& Higgins 1998). It was shown that one of the PSA patterns is the response to the El Niño Southern Oscillation (Karoly 1989) which suggests a tropical origin of eastward propagating wave-train patterns that influence Southern Hemisphere variability. Mo \& Higgins (1998) showed that the two PSA modes represent the intraseasonal oscillation in the Southern Hemisphere with periods of roughly 40 days and the evolution of the PSA modes shows a coherent eastward propagation. The pattern associated with temperature, wind and sea level pressure variability, as captured by the PC1, shows also an eastward propagation (Fig. 8). Strong connection of tropical processes with Antarctic climate was identified (Carvalho et al. 2005, Fogt \& Bromwich 2006, Fogt et al. 2010) which is an additional argument for a tropical origin of the atmospheric circulation pattern associated to the dominant mode of $\mathrm{T}, \mathrm{U}$, and SLP intraseasonal variability recorded at Neumayer Station.

PC2 of T, U and SLP shows enhanced variability in the intraseasonal band with peaks at $\sim 35, \sim 60$ and $\sim 120$ days. The atmospheric circulation pattern associated with this mode (Fig. 11) projects strongly on the SAM/AAO. Empirical mode decomposition applied to the daily SAM/ AAO index reveals the existence of strong periodic signals at 35 days, 63 days and 117 days (Pohl et al. 2010), which can be related to the corresponding peaks in our PC2 spectrum. Although these peaks are in the range of tropical MJO variability, they cannot be attributed to the MJO signature on SAM/AAO variability. A recent study (Pohl et al. 2010) showed that the interaction between MJO and SAM/AAO is very weak. The MJO is associated with regional-scale cyclonic or anticyclonic anomalies that tend to propagate eastward and which cannot produce a generalized mass transfer between the polar region and mid-latitudes as is the case for AAO. Therefore, these peaks in the PC2 spectrum are probably related to internal dynamic processes of the polar atmosphere including those related to the SAM/AAO.

The results presented in this paper suggest that tropical processes and higher latitude processes are related to distinct anomaly patterns of the meteorological variables measured at Neumayer, and that these patterns have specific temporal oscillatory components. In a forthcoming paper we analyse the variability of climatic variables recorded at Neumayer from semi-annual to decadal timescales. The results presented in this paper could lead to a significant improvement in the interpretation of the ice core variability and its relationship with atmospheric circulation in the Southern Hemisphere.

\section{Acknowledgements}

We are grateful to the journal editor, Dr L. Padman, and two anonymous reviewers for their constructive comments and detailed edits which lead to a significant improvement of the manuscript. This research was supported by AWI through REKLIM project. Necula Cristian was supported by the POSDRU/89/1.5/S/58852 project "Postdoctoral programme for training scientific researchers" co-financed by the European Social Fund within the Sectorial Operational Programme Human Resources Development 2007-13.

\section{References}

AокI, S. 2002. Coherent sea level response to the Antarctic Oscillation. Geophysical Research Letters, 10.1029/2002GL015733.

Carvalho, L.M., Jones, C. \& Ambrizzi, T. 2005. Opposite phases of the Antarctic Oscillation and relationship with intraseasonal to interannual activity in the tropics during the austral summer. Journal of Climate, 18, $702-718$.

Dima, M. \& Lohmann, G. 2004. Fundamental and derived modes of climate variability. Application to biennial and interannual timescale. Tellus, 56A, 229-249.

Donald, A., Meinke, H., Power, B., Maia, A. De H.N., Wheeler, M.C., White, N., Stone, R.C. \& RibBe, J. 2006. Near-global impact of the Madden-Julian Oscillation and the North Atlantic Oscillation. Geophysical Research Letters, 10.1029/2005GL025155.

Fogt, R.L. \& BRomwich, D.H. 2006. Decadal variability of the ENSO teleconnection to the high latitude South Pacific governed by coupling with the Southern Annular Mode. Journal of Climate, 15, 979-997.

Fogt, R.L., BRomwich, D.H. \& Hines, K.M. 2010. Understanding the SAM influence on the South Pacific ENSO teleconnection. Climate Dynamics, 36, 1555-1576.

Ghil, M., Allen, M.R., Dettinger, M.D., et al. 2002. Advanced spectral methods for climatic time series. Review Geophysics, 40, 3.1-3.41.

Hsu, H.-H. \& Weng, S.-P. 2002. Stratospheric Antarctic intraseasonal oscillation during the austral winter. Journal of the Meteorological Society of Japan, 80, 1029-1050.

Justus, C.G., Hargraves, W.R., Mikail, A. \& Graber, D. 1978. Methods for estimating wind speed frequency distributions. Journal of Applied Meteorology, 17, 350-353.

Kalnay, E., Kanamitsu, M., Kistler, R., et al. 1996. The NMC/NCAR 40-year reanalysis project. Bulletin American Meteorology Society, 77, 437-471.

Kanamitsu, M., Ebisuzaki, W., Woollen, J., Yang, S-K., Hnilo, J.J., Fiorino, M. \& PotTer, G.L. 2002. NCEP-DOE AMIP-II reanalysis (R-2). Bulletin of the American Meteorological Society, 83, 1631-1643. 
Karoly, D.J. 1989. Southern Hemisphere circulation features associated with El Niño-Southern Oscillation. Journal of Climate, 2, 1239-1252.

Kistler, R., Kalnay, E., Collins, W., et al. 2001. The NCEP-NCAR 50-year reanalysis: monthly means CD-ROM and documentation. Bulletin of the American Meteorological Society, 82, 247-267.

Kushner, P.J. \& LeE, G. 2007. Resolving the regional signature of annular modes. Journal of Climate, 20, 2840-2852.

KönIG-LANGLO, G. 2012. Validation routines for synoptic observations. Bremerhaven: Alfred Wegener Institute for Polar and Marine Research, hdl:10013/epic.40293.d0001.

König-Langlo, G. \& Herber, A. 1996. The meteorological data of the Neumayer Station (Antarctica) for 1992, 1993 and 1994. Berichte Polarforschung, 187, 104 pp.

König-Langlo, G. \& Loose, B. 2007. The meteorological observatory at Neumayer Station (GvN and NM-II) Antarctica. Polarforschung, 76, 25-38.

MadDEn, R.A. \& Julian, P.R. 1994. Observation of the 40-50 day tropical oscillation. A review. Monthly Weather Review, 122, 814-837.

Matthews, A.J. \& Meredith, M.P. 2004. Variability of Antarctic circumpolar transport and the Southern Annular Mode associated with the Madden-Julian Oscillation. Geophysical Research Letters, 10.1029/ 2004GL021666.

Mo, K.C. \& Higgins, R.Y. 1998. The Pacific-South American Modes and tropical convection during the Southern Hemisphere winter. Journal of Climate, 126, 1581-1596.

Okumura, Y.M., Schneider, D., Deser, C. \& Wilson, R. 2012. Decadalinterdecadal climate variability over Antarctica and linkages to the tropics: analysis of ice cores, instrumental, and tropical proxy data. Journal of Climate, 25, 7421-7441.

Pohl, B., Fauchereau, N., Reason, C.J.C. \& Rouault, M. 2010. Relationship between the Antarctic Oscillation, the Madden-Julian, ENSO, and consequences for rainfall analysis. Journal of Climate, 23, 238-254.
Rimbu, N., Lohmann, G., König-Langlo, G., Necula, C. \& Ionita, M. 2012. 30 years of synoptic observations from Neumayer Station with links to datasets. Dataset \#804156. 10.1594/PANGAEA.804156.

Schneider, D.P., Okumura, Y. \& Deser, C. 2012. Observed Antarctic interannual climate variability and tropical linkages. Journal of Climate, 25, 4048-4066.

Stockwell, R.W.G., Riggin, D.M., French, W.J.R., Burns, G.B. \& Murphy, D.J. 2007. Planetary waves and intraseasonal oscillations at Davis, Antarctica, from undersampled time series. Journal Geophysical Research, 10.1029/2006JD008034.

Thompson, D.W. \& Wallace, J.M. 2000. Annular modes in the extratropical circulation. Part I: month-to-month variability. Journal of Climate, 13, 1000-1016.

Torrence, C. \& Compo, G.P. 1998. A practical guide to wavelet analysis. Bulletin of the American Meteorological Society, 79, 61-78.

VAN DEN BRoEKe, M.R. 1998. The semi-annual oscillation and Antarctic climate. Part 1: influence on near surface temperatures (1957-79). Antarctic Science, 10, 175-183.

Von Storch, H. \& Zwiers, F.W. 1999. Statistical analysis in climate research. Cambridge: Cambridge University Press, $484 \mathrm{pp}$.

WANG, X. \& ZeNDER, C.S. 2011. Arctic and Antarctic diurnal and seasonal variations of snow albedo from multiyear Baseline Surface Radiation Network measurements. Journal of Geophysical Research, 10.1029/ $2010 J F 001864$.

WheELER, M.C. \& Hendon, H.H. 2004. An all-season real-time MJO index: development of an index for monitoring and prediction. Monthly Weather Review, 132, 1917-1932.

YASUNARY, T. \& Kodama, S. 1993. Intraseasonal variability of katabatic wind over East Antarctica and planetary flow regime in the Southern Hemisphere. Journal of Geophysical Research - Atmosphere, 98, $13063-13070$. 